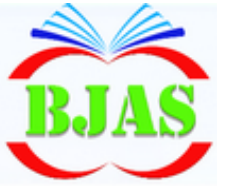

Available online at http://bajas.edu.iq

https://doi.org/10.37077/25200860.2021.34.sp1.2

College of Agriculture, University of Basrah

Basrah Journal

of Agricultural

Sciences

ISSN 1814 - 5868 Basrah J. Agric. Sci., 34(Special Issue 1): 11-20, 2021

E-ISSN: 2520-0860

\title{
Feasibility Study of 3D Printed Materials for an Ammonia Emission Passive Sampler
}

Sabrina Jaeman**1, Khairudin Nurulhuda*1, Adibah Mohd Amin², Muhammad Firdaus Sulaiman², Hasfalina Che Man ${ }^{1}$, Anas Mohd Mustafah ${ }^{1}$, \& Nurul Syaadah Gusni $^{1}$

${ }^{1}$ Department of Biological and Agricultural Engineering, Faculty of Engineering, Universiti Putra Malaysia, 43400 Serdang, Selangor, Malaysia

${ }^{2}$ Department of Land Management, Faculty of Agriculture, Universiti Putra Malaysia, 43400 Serdang, Selangor, Malaysia

*Corresponding author E-mail: k_nurulhuda@upm.edu.my;** sabrina.jaeman@gmail.com Received 31 March 2020; Accepted 29 February 2021; Available online 19 August 2021

\begin{abstract}
Ammonia $\left(\mathrm{NH}_{3}\right)$ emission accounts for a loss of 10 to $60 \%$ of the total nitrogen input in rice fields. $\mathrm{NH}_{3}$ in the air reacts with sulphuric acid, nitric acid and hydrochloric acid to form ammonium salt, which increases the concentration of PM2.5 particles in the atmosphere. These fine particles can cause respiratory problems. A reliable $\mathrm{NH}_{3}$ sampler is important in order to quantify the $\mathrm{NH}_{3}$ emission. The objective of this study is to evaluate the suitability of three 3D printed materials, namely acrylonitrile-butadiene-styrene (ABS), polylactic acid (PLA) and polypropylene (PP) compared to stainless steel and glass, as the interior material of an $\mathrm{NH}_{3}$ passive sampler for use with the chemical-trap approach; Stainless steel and glass are typically used for construction of the $\mathrm{NH}_{3}$ passive sampler. The sample plates were coated with acetone with $3 \%$ oxalic acid and tested in closed static chambers with three different $\mathrm{NH}_{3}$ sources. ABS, PP and PLA tolerated the acetone solution with PP being the least reactive. However, PP heavily warped during 3D-printing resulting in a deformed shape. Performance of coated $\mathrm{ABS}$ plates in trapping $\mathrm{NH}_{3}$ is similar to stainless steel and glass plates.
\end{abstract}

Keywords: Ammonia volatilization, passive sampler, 3D printing

\section{Introduction}

Ammonia $\left(\mathrm{NH}_{3}\right)$ volatilization is one of the dominant pathways of nitrogen $(\mathrm{N})$ loss in rice fields (Yan et al., 2011; Soares et al., 2012; $\mathrm{Xu}$ et al., 2012). $\mathrm{NH}_{3}$ emission accounts for a loss of 10 to $60 \%$ of the total $\mathrm{N}$ input (Fillery et al., 1984; Chen et al., 2014).
Minimizing NH3 emission in agricultural systems is important from agronomic, ecologic, and economic standpoints (Yang et al., 2019). $\mathrm{NH}_{3}$ emission have negative effects on the environment and human health. Gaseous $\mathrm{NH}_{3}$ react with sulfuric acid, nitric 


\section{Sabrina et al. / Basrah J. Agric. Sci., 34(Special Issue 1): 11-20, 2021}

acid and hydrochloric acid to form ammonium salt, which increases the concentration of PM2.5 particles in

Micrometeorological techniques (Meade et al., 2011) and wind tunnel systems (Gong et al., 2013) are suggested for measuring $\mathrm{NH}_{3}$ emissions in agricultural fields due to its precision, low detection limit and high accuracy (Yang et al., 2019), but the simpler and cheaper closed chamber methods are favored and used in field research (Wang et al., 2004; Yang et al., 2015). However, compared to the micrometeorological methods, the measurements obtained through the closed chamber methods may result in uncertainty as the chambers may alter the natural conditions such as wind effect (Wang et al., 2018). Some of the micrometeorological methods are implemented with passive $\mathrm{NH}_{3}$ samplers such as the Leuning's sampler (Leuning et al., 1985; Meade et al., 2011). The interior of the Leuning's sampler is constructed with stainless steel (Leuning et al., 1985).

Current 3D printing technology may allow for fabrication of products of complex shape with reduction in manufacturing cost and time compared to the conventional manufacturing techniques ( $\mathrm{Yu}$ et al., 2019). The 3D printing refers to a class of technologies for the direct fabrication of physical products from a 3D computer aided engineering (CAD) model by a layered manufacturing. Among the materials that can be used for $3 \mathrm{D}$ printing are acrylonitrile butadiene styrene, polylactic acid and polypropylene. Acrylonitrile butadiene styrene (ABS) is a cost-effective engineering polymer that is easy to machine and fabricate, with good impact and chemical resistance, high aesthetic qualities, and decent strength and stiffness (Wojtyla et al., 2017). Polylactic atmospheric pollutants (Zhang et al., 2013). Currently, there is lack of published report on $\mathrm{NH}_{3}$ emission from Malaysian rice fields.

acid (PLA) is a synthetic, aliphatic polyester - a compostable, biodegradable thermoplastic obtained from renewable sources (Jamshidian et al., 2010). PLA is thermally unstable and shows a fast loss of molecular weight in the course of thermal treatment. PLA tends to be slightly more brittle than other plastics (Srivatsan \& Sudarshan, 2015). Meanwhile, polypropylene (PP) is tough and has a good fatigue resistance making it ideal for low strength applications like living hinges, straps, leashes (SIMPLIFY3D®, 2019).

A reliable $\mathrm{NH}_{3}$ passive sampler is an important tool in order to quantify the $\mathrm{NH}_{3}$ emissions from agricultural systems. Therefore, the objective of this study is to evaluate the suitability of three $3 \mathrm{D}$ printed materials as the interior material of an $\mathrm{NH}_{3}$ passive sampler for use with the chemicaltrap approach compared to stainless steel and glass; Stainless steel and glass are typically used for construction of the $\mathrm{NH}_{3}$ passive sampler. The three specific objectives are as follows: i) to compare durability of ABS, PLA, PP, stainless steel and glass in chemical trap solution which is acetone with $3 \%$ oxalic acid, ii) to quantify the amount of $\mathrm{NH}_{3}$ trapped by each material, and iii) to evaluate feasibility of the $3 \mathrm{D}$ printed materials as a substitute to stainless steel and glass

\section{Materials \& Methods}

\section{Sample plates}

Five sample materials, namely acrylonitrilebutadiene-styrene (ABS), polylactic acid (PLA), polypropylene (PP), glass, and stainless steel, were compared in this study. The three 3D printed materials were selected 
due to their differences in chemical and physical properties. ABS, PLA and PP plates were purchased from FUMO Solutions 3D printing services, while glass and stainlesssteel plates were purchased from local glass and steel manufacturers, respectively. The dimension of each sample plate was $30 \mathrm{~mm} \times$ $40 \mathrm{~mm} \times 3 \mathrm{~mm}$.

\section{Closed static chamber experiments}

A closed static chamber method (Fig. 1) was used in this research (modified after Yang et al., 2019). Fifteen closed static chambers were set up in the laboratory. Each of the closed chamber had a height of $120 \mathrm{~mm}$, diameter $116 \mathrm{~mm}$, and is made of polyethylene terephthalate (PET). A petri dish filled with a mixture of solutions as shown in table (1) was placed in each chamber as an $\mathrm{NH}_{3}$ source. Five of the chambers had no $\mathrm{NH}_{3}$ source, another five had $1 \mathrm{X}$ (one-time strength) $\mathrm{NH}_{3}$ source and the other five had $4 \mathrm{X}$ (four times strength) $\mathrm{NH}_{3}$ source. Sample plates of different materials were placed in each of the five chambers.

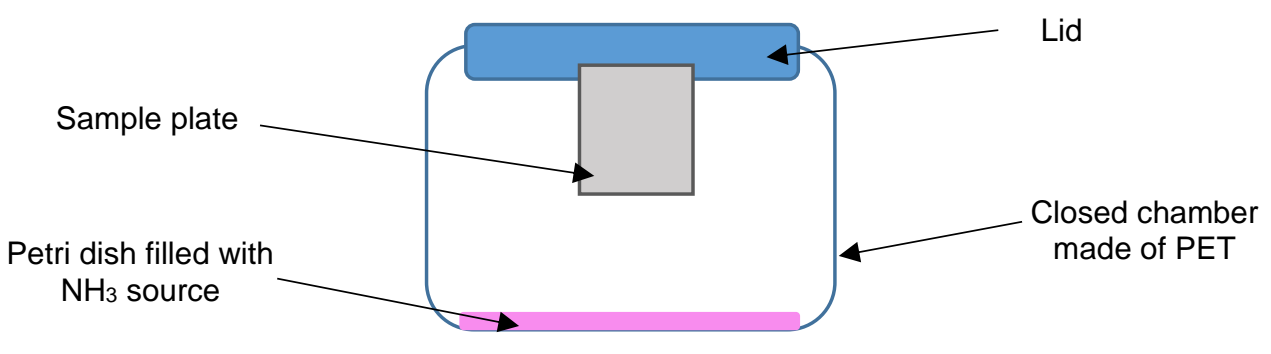

Fig. (1): Schematic diagram of a closed static chamber with a sample plate and an $\mathrm{NH}_{3}$ source.

Three sample plates of each material were dipped into a mixture of acetone and $3 \%$ oxalic acid and subsequently air dried. Next, each of the plate was hung at the top of each closed static chamber to act as an $\mathrm{NH}_{3}$ trap.
The amount of $\mathrm{NH}_{3}$ trapped by the plates were measured after 4 hours exposure. The experiment was repeated for another two exposure durations of 18 and 24 hours.

Table (1): Setup of $\mathrm{NH}_{3}$ sources.

\begin{tabular}{cccc}
\hline \multirow{2}{*}{$\begin{array}{c}\text { Concentration of } \\
\text { ammonia source }\end{array}$} & $\begin{array}{c}\text { Ammonium sulfate } \\
\left(\mathrm{NH}_{4}\right)_{2} \mathrm{SO}_{4} \\
\left(22.7 \mathrm{mmol}^{-1}\right)\end{array}$ & Water & $\begin{array}{c}\text { Sodium hydroxide } \\
\text { NaOH } \\
\left(12.5 \mathrm{~mol}^{-1} \mathrm{~L}^{-1}\right)\end{array}$ \\
\hline $0 \mathrm{X}$ & 0 & 2 & 2 \\
\hline $1 \mathrm{X}$ & 0.5 & 1.5 & 2 \\
\hline $4 \mathrm{X}$ & 2 & 0 & 2 \\
\hline
\end{tabular}

Note: $0 \mathrm{X}$ is no $\mathrm{NH}_{3}$ source, $1 \mathrm{X}$ is one-time strength of $\mathrm{NH}_{3}$ source and $4 \mathrm{X}$ is four times strength of $\mathrm{NH}_{3}$ source.

The $\mathrm{NH}_{3}$ trapped by the plates was extracted by dipping and shaking the plates in $40 \mathrm{~mL}$ of distilled water. The $4500-\mathrm{NH}_{3} \mathrm{~F}$ Phenate method was used to analyze the sample solutions for $\mathrm{NH}_{3}$ (American Public Health Association, 1999). Thereafter, $1 \mathrm{~mL}$ of phenol solution, $1 \mathrm{ml}$ of sodium nitroprusside solution and $2.5 \mathrm{ml}$ of oxidizing 
solution were added to a $25 \mathrm{~mL}$ sample solution in a $50 \mathrm{ml}$ conical flask and mixed well. The samples were then covered with parafilm and left for at least 1 hour in subdued light to allow the colour to develop. Absorbance of each sample solution was then measured with a spectrophotometer (CE1011 1000 series, manufactured by Cecil instruments). The wavelength of the spectrophotometer was set at $640 \mathrm{~nm}$ as stated in the $4500-\mathrm{NH}_{3} \mathrm{~F}$ Phenate method. The absorbance readings were then compared to a calibration curve. In a case where the concentration of $\mathrm{NH}_{3}$ exceeds the maximum value on the calibration curve, the sample solution was diluted with distilled water and then analysed again with the spectrophotometer. Subsequently, the resulting $\mathrm{NH}_{3}$ concentration obtained for the sample solution was multiplied with the dilution factor.

Prior to the determination of $\mathrm{NH}_{3}$ in the sample solutions, a calibration curve was prepared for $0,0.01,0.05,0.1,0.5,1$, and 5 $\mathrm{mg} \mathrm{N} \mathrm{L}{ }^{-1}$ standard solutions. Similarly, the
4500- $\mathrm{NH}_{3} \mathrm{~F}$ Phenate method was used to analyze the solutions for $\mathrm{NH}_{3}$. A blank was prepared by replacing the standard solution with distilled water. A graph of absorbance against concentration of $\mathrm{NH}_{3}$ was constructed.

\section{Results \& Discussion}

\section{Practicality of 3D printing of sample plates with ABS, PLA and PP materials}

3D printing process adds material layer by layer to construct the end products. When plastics are printed, they first expand slightly, but contract as they cool down. This causes warping to occur due to material shrinkage which could lead to shape and dimensional inaccuracy (deformation). ABS, PLA, and PP plates have different shrinkage factors as shown in table (2). PLA is among the easier materials to print and the shrinkage rate of PLA is between 0.3 to $0.5 \%$ (Kochesfahani, 2016). PLA prints at a lower temperature that ranges between 190 and $220^{\circ} \mathrm{C}$ (SIMPLIFY3D®, 2019).

Table (2): Printing properties of the 3D plates.

\begin{tabular}{cccc}
\hline Material & Shrinkage factor, $\%$ & Extruder temperature, ${ }^{\circ} \mathrm{C}$ & References \\
\hline ABS & 0.7 to 1.6 & 220 to 250 & $\begin{array}{c}\text { Kochesfahani (2016); } \\
\text { SIMPLIFY3D® (2019) }\end{array}$ \\
\hline PLA & 0.3 to 0.5 & 190 to 220 & $\begin{array}{c}\text { Kochesfahani (2016); } \\
\text { SIMPLIFY3D }(2019)\end{array}$ \\
\hline PP & 1.0 & 220 to 250 & $\begin{array}{c}\text { Gordon (2016); } \\
\text { SIMPLIFY3D }(2019)\end{array}$ \\
\hline
\end{tabular}

Meanwhile, ABS is tough and have a high melting point. Therefore, the ABS must be heated to a higher temperature between 220 and $250^{\circ} \mathrm{C}$ to print the objects. The shrinkage factor of the ABS is from 0.7 to $1.6 \%$ which is higher than that of PLA. Meanwhile, PP is a semi-rigid and lightweight material that is commonly used in storage and packaging applications. The semi-crystalline structure of the material causes the $3 \mathrm{D}$ printed parts to heavily warp upon cooling (SIMPLIFY3D®, 2019). Gordon (2016) reported a shrinkage factor of about $1 \%$ for the PP. The PP can print well at low temperatures, but printing at 
slightly higher temperatures in the 220 to 250

${ }^{\circ} \mathrm{C}$ range may help to create a stronger part (SIMPLIFY3D®, 2019).

Visual inspection of the 3D printed sample plates indicates that the PLA sample plates had the most accurate dimensions compared to ABS and PP plates. The PLA plates had uniform thicknesses and the surfaces of the plates were slightly rough. Meanwhile, the ABS plates were slightly bent, and the thicknesses of the sample plates were slightly uneven. The PP sample plates were also bent. The thicknesses of the plates were also uneven and with crust at the corners of the plates. Moreover, one side of the PP plates was sticky due to an adhesive tape that had to be used to keep the plate flat during printing to reduce heavy warping.

\section{Standard calibration curve of $4500-\mathrm{NH}_{3} \mathrm{~F}$ Phenate method}

The value of absorbance increased as the $\mathrm{NH}_{3}$ concentration increased. The calibration curve was obtained by plotting a graph of absorbances against $\mathrm{NH}_{3}$ concentrations (Fig. 2), where the $R^{2}$ is 0.9989 and $R$ is 0.999 . The standard calibration curve follows the Beer's law, where the absorbances are proportional to the concentrations (Brubaker, 2018).

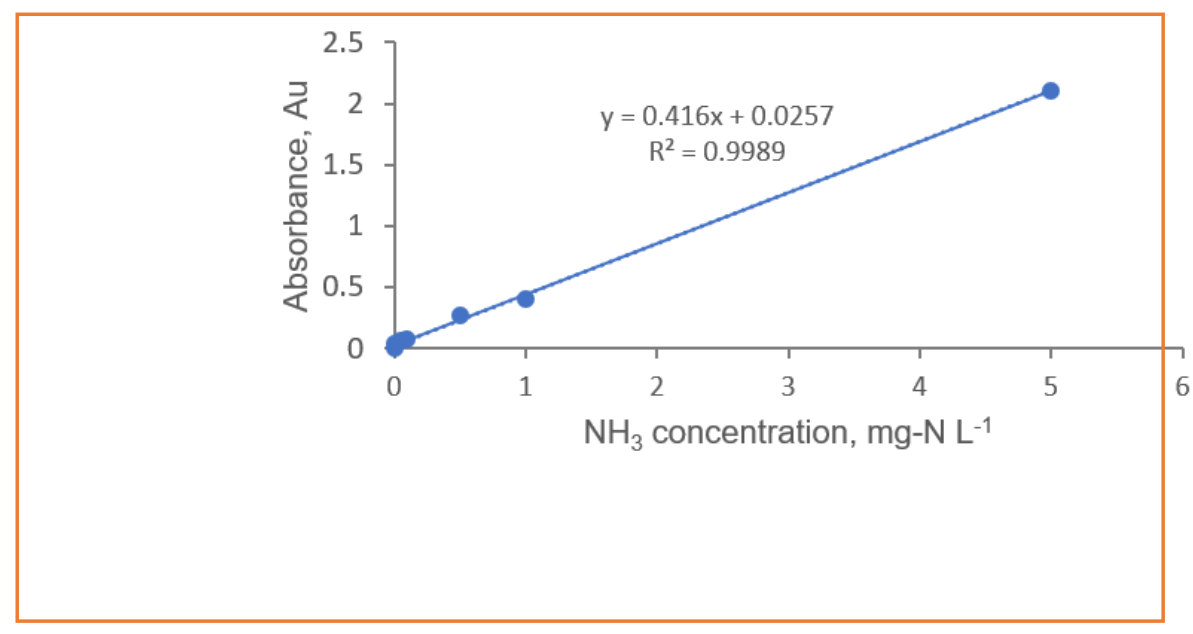

Fig. (2): Standard calibration curve of absorbance against $\mathrm{NH}_{3}$ concentration

\section{Durability of sample plates in acetone solution}

In order to trap $\mathrm{NH}_{3}$ on the sample plates, each of the plate was dipped in acetone solution with $3 \%$ oxalic acid. Acetone is a colourless liquid that has a distinct smell and taste. Acetone is a polar aprotic solvent that can produce a variety of organic chemical reactions (Deepak et al., 2019). Table (3) reports the visual inspection on the durability of each plate material after each dip in the acetone with 3\% oxalic acid. Physical conditions of the plates before and after dips are shown in fig. (3).

For stainless steel and glass, there was no apparent change on the physical properties of the materials after each dip. As for the 3Dprinted materials, all materials tolerated the acetone solution, without being fully dissolved even after the fourth dips. However, PP showed highest resistance to the acetone solution and this observation is in agreement with Wittbrodt \& Pearce (2015). 
Sabrina et al. / Basrah J. Agric. Sci., 34(Special Issue 1): 11-20, 2021

Table (3): Visual inspection of the durability of plate materials after a quick dip in acetone with $3 \%$ oxalic acid

\begin{tabular}{|c|c|c|c|c|}
\hline \multirow[t]{2}{*}{ Plate material } & \multicolumn{4}{|c|}{ Number of dips } \\
\hline & 1 time & 2 times & 3 times & 4 times \\
\hline Stainless steel & $* * *$ & $* * *$ & $* * *$ & $* * *$ \\
\hline Glass & $* * *$ & $* * *$ & $* * *$ & $* * *$ \\
\hline $\mathrm{PP}$ & $* * *$ & $* * *$ & $* * *$ & $* * *$ \\
\hline PLA & $* * *$ & $* *$ & $* *$ & $* *$ \\
\hline ABS & $* *$ & $* *$ & $* *$ & $* *$ \\
\hline
\end{tabular}

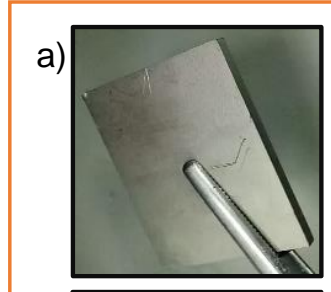

f)

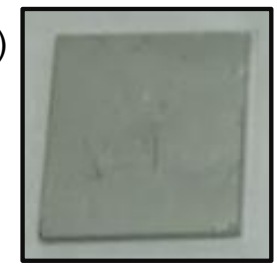

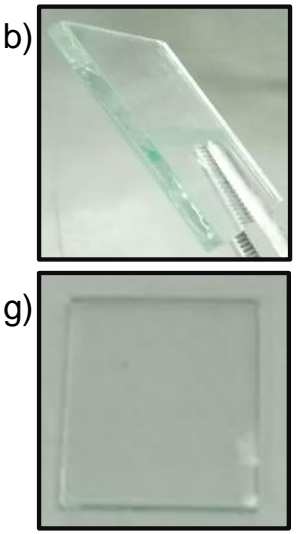

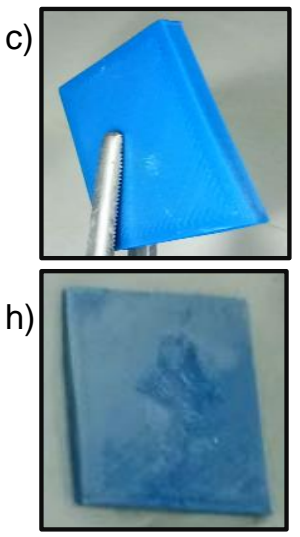

d)

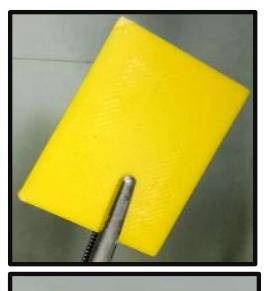

i)

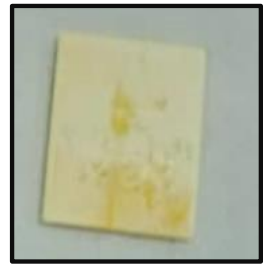

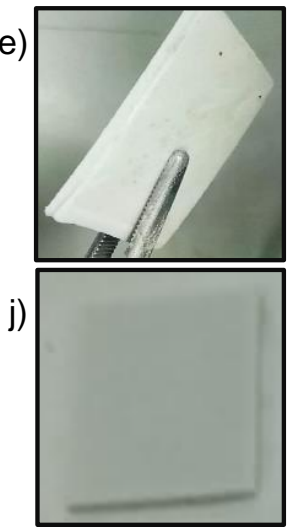

Fig. (3): Effects of acetone on the 3D printed plates: a) Stainless steel, b) glass, c) ABS, d) PLA and e) PP plates before a dip in acetone, and f) stainless steel, g) glass, h) ABS, i) PLA and j) PP plates after 3 dips in acetone with $3 \%$ oxalic acid.

Nevertheless, the PP plates were already deformed before the dip due to heavy warping during printing (Fig. 3e). Wittbrodt $\&$ Pearce (2015) reported poor compatibility of ABS virgin filament with acetone. Similarly, in this study, it was observed that the ABS plates were less resistance to the acetone solution than the PP plate. After dipping the ABS sample plates for the first time, it was observed that the material slightly dissolved in the acetone solution resulting in a cloudy solution. The dip also eliminated any visible and rough lines on the sample plates and resulted in a clean and smooth surface finish. PLA in pure form is claimed not reactive to acetone. Natural PLA (no dye added) contains the lower percent of crystalline (Wittbrodt \& Pearce, 2015). In this study, the PLA material used was a dyed PLA, which may affect the percent crystallinity of the printed materials. After two dips in the acetone solution, the yellow colour of the PLA plates faded. The materials did not dissolve in the acetone solution as the solution remained clear. However, the sample plates slightly swelled-up and the surface had a rubbery-feels at the end of the experiment. 
Comparison of ammonia ( $\left.\mathrm{NH}_{3}\right)$ trapped by the five sample plates under three duration exposures and three ammonia sources

Stainless steel is used to construct the interior of the a Leuning's $\mathrm{NH}_{3}$ passive sampler (Leuning et al., 1985). Therefore, in this study, the amount of $\mathrm{NH}_{3}$ trapped by the stainless steel was used as the baseline for comparisons with other sample plates.

Fig. (4a). shows the trends of total $\mathrm{NH}_{3}$ trapped by the stainless steel, glass, ABS, PLA, and PP plates in the closed chambers with no $\mathrm{NH}_{3}$ source across three exposure durations, i.e., 4 hours, 18 hours and 24 hours. The total $\mathrm{NH}_{3}$ trapped by all five sample plates are negligible for all three exposure durations.

Fig. (4b) shows the trends of total $\mathrm{NH}_{3}$ trapped by the stainless steel, glass, PLA, PP and $\mathrm{ABS}$ plates in the closed chambers with $1 \mathrm{X} \quad \mathrm{NH}_{3}$ source across three exposure durations. The range of $\mathrm{NH}_{3}$ trapped by all five plates after 4 hours exposure was from $0.03 \mathrm{mg} \mathrm{N}$ to $0.08 \mathrm{mg} \mathrm{N}$. For the 18 hours exposure, the amount of $\mathrm{NH}_{3}$ trapped by the stainless steel, glass and ABS plates only slightly increased (i.e., $0.1 \mathrm{mg} \mathrm{N}$ to $0.4 \mathrm{mg} \mathrm{N}$ ), but a sudden peak of $\mathrm{NH}_{3}$ was observed for PP (1.1 mg N) plates. The $\mathrm{NH}_{3}$ trapped by the PLA and PP plates after 24 hours exposure was lower than those after 18 hours exposure (i.e., <0.11 mg N).

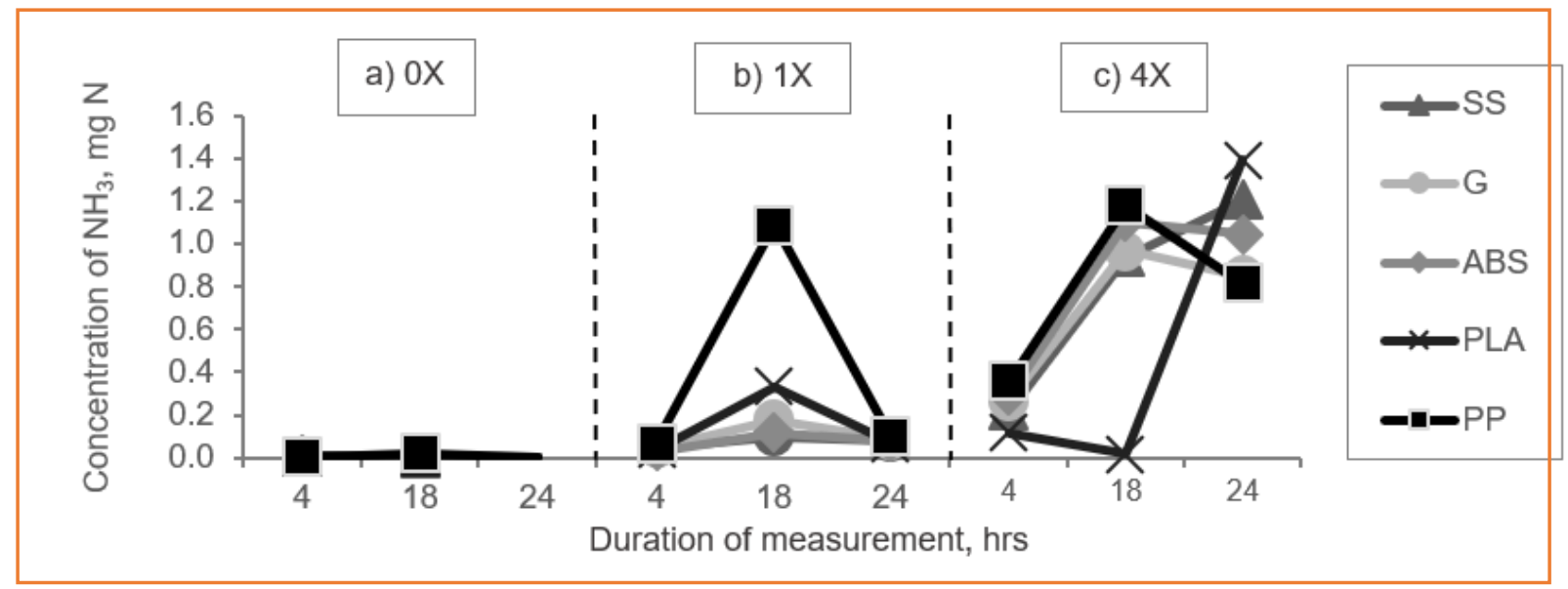

Fig. (4): Comparison of $\mathrm{NH}_{3}$ trapped by stainless steel, glass, ABS, PLA and PP after 4, 18and 24-hours exposure for 3 ammonia strength sources: a) $0 \mathrm{X}$ b) $1 \mathrm{X}$ and c) $4 \mathrm{X}$.

Fig. (4c). reveals the trends of total $\mathrm{NH}_{3}$ trapped by the stainless steel, glass, PLA, PP and ABS plates in the closed chambers with $4 \mathrm{X} \quad \mathrm{NH}_{3}$ source across three exposure durations. Stainless steel plate was the only material that exhibit steady increase in total $\mathrm{NH}_{3}$ trapped over time. The trends of total $\mathrm{NH}_{3}$ trapped by the ABS and glass plates were comparable. A slight dip in the total $\mathrm{NH}_{3}$ trapped was observed for the ABS and glass plates after 24 hours exposure duration.
Yang et al. (2019) used boric acid to trap $\mathrm{NH}_{3}$ emitted from similar strength of $\mathrm{NH}_{3}$ source showed that the longer exposure resulted in higher $\mathrm{NH}_{3}$ emission. In the $4 \mathrm{X}$ $\mathrm{NH}_{3}$ source treatment, longer exposure also resulted in higher $\mathrm{NH}_{3}$ emission, except for the PLA plate.

Overall, fig. (4) explains that the PP and PLA plates exhibited inconsistent trends in the amount $\mathrm{NH}_{3}$ trapped. An unexpected spike in the amount of $\mathrm{NH}_{3}$ trapped by the PP 
was observed after 18 hours exposure duration to the $1 \mathrm{X} \mathrm{NH}_{3}$ source. Meanwhile, the PLA plate had a negligible amount of $\mathrm{NH}_{3}$ after 18 hours exposure duration to a $4 \mathrm{X}$ $\mathrm{NH}_{3}$ source. Typically, the liquid sample would turn blue in the $4500 \mathrm{~F}$ Phenate method; colour ranges from light blue to dark blue as the $\mathrm{NH}_{3}$ concentration increased. It was observed that the colour of the solution was neither light nor dark blue, but a clear grey solution was observed for this specific PLA plate after 18 hours exposure.

In this study, the same 3D printed plates were repeatedly used to study the effects of exposure durations. The physical changes to the some of the plates' surfaces due to the reactions of the $3 \mathrm{D}$ printed sample plates with the acetone solution may have affected the capacity of the coated plates to trap $\mathrm{NH}_{3}$ emission over time. The coated plates may also reach saturation with $\mathrm{NH}_{3}$ when exposure duration was 24 hours compared to 18 hours for the treatment with the highest concentration of $\mathrm{NH}_{3}$ source.

Fig. (5) demonstrates the trends of each materials in trapping the $\mathrm{NH}_{3}$ emission for different $\mathrm{NH}_{3}$ sources and exposure durations. From fig. (5), it was apparent that the PLA and PP plates showed inconsistence performances and the trends deviated from those of stainless steel, glass and ABS plates. The sticky surface of PP sample plates may have affected the coating of acetone solution with $3 \%$ of oxalic acid contributing to the inconsistence performance of the material. ABS showed a consistence performance compared to stainless steel except that the amount of $\mathrm{NH}_{3}$ emission trapped at 18 hours was higher than 24 hours, but the difference was minimal. It is plausible that the sample plate of ABS was saturated with $\mathrm{NH}_{3}$ after 24 exposure duration.

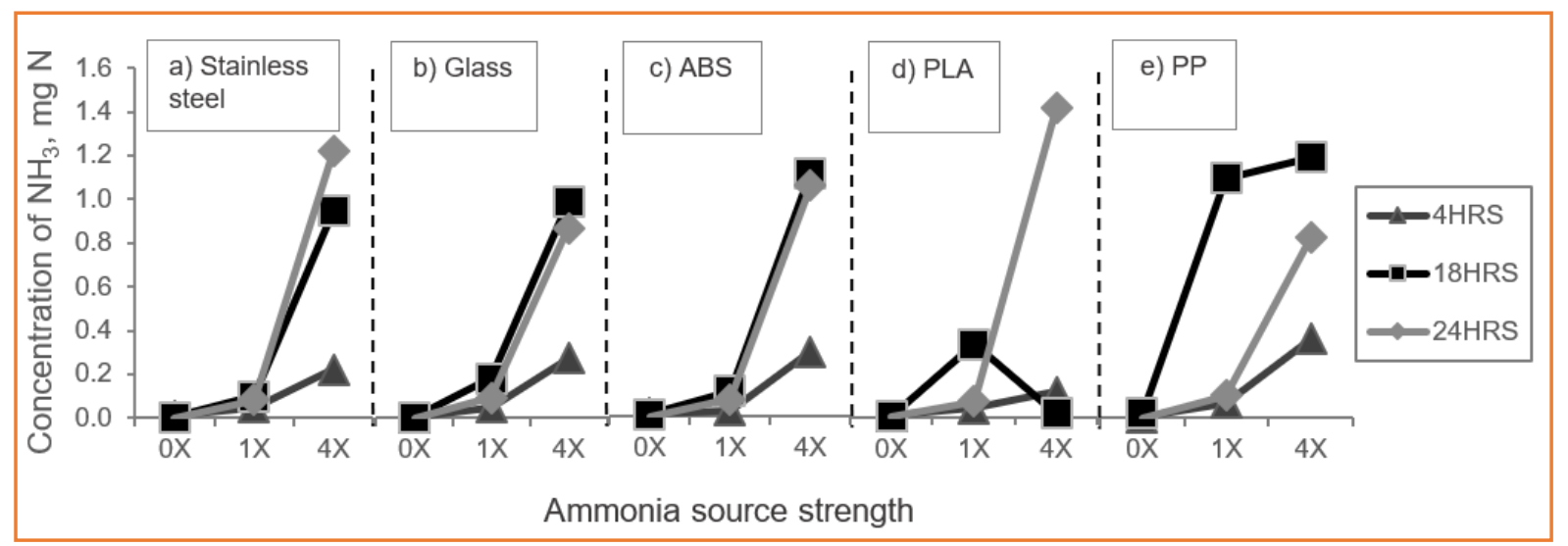

Fig. (5): $\mathrm{NH}_{3}$ trapped by different material: a) Stainless steel, b) glass, c) ABS, d) PLA, and e) PP for three $\mathrm{NH}_{3}$ sources.

\section{Conclusions}

This study showed that ABS, PP and PLA sample plates tolerated the acetone solution with $3 \%$ oxalic acid. Of all 3D printed plates, $\mathrm{PP}$ was the least reactive with acetone and had similar durability as the stainless steel and glass plates after dips in the acetone solution. The ABS and PLA plate showed minor to moderate deformation. However, PP plates were the most difficult to print due to heavy warping, which consequently resulted 


\section{Sabrina et al. / Basrah J. Agric. Sci., 34(Special Issue 1): 11-20, 2021}

in deformed PP plates even before the dip in the acetone solution.

The amount of ammonia trapped by the ABS plates was comparable to those of stainless steel and glass plates. Meanwhile, the trends of ammonia trapped observed for the PLA and PP plates deviated from those of the stainless steel and glass plates.

The study on durability of the plates in acetone solution and the amount of $\mathrm{NH}_{3}$ trapped by the plates demonstrated that the ABS plate may be a viable alternative to stainless steel and glass plates. Further study is needed to investigate whether the material is suitable to be used as a full-sized $\mathrm{NH}_{3}$ passive sampler as opposed to the small-sized plate.

\section{Acknowledgement:}

The authors would like to acknowledge the financial support provided by the Ministry of Education Malaysia through the Fundamental Research Grant Scheme FRGS/1/2019/WAB01/UPM/02/5 Project Code 07-01-19-2081FR [Grant No. 5540206].

\section{References:}

American Public Health Association (1999). Standard Methods for the Examination of Water and Wastewater, Clesceri, L. S., Greenberg, A. E., \& Eaton, A. D. (Editors.), American Public Health Association, 20 ${ }^{\text {th }}$ Edition, American Water Works Association, Water Environment Federation.

Brubaker, J. (2018). How to calculate concentration using absorbance using Beer's law theory vs. practice. Retrieved on $16^{\text {th }}$ July 2020 https://sciencing.com/calculate-concentrationusing-absorbance-7153267.html

Chen, X., Cui, Z., Fan, M., Vitousek, P., Zhao, M., Ma, W., Wang, Z., Zhang, W., Yan X. , Yang, J., Deng, X. Gao, Q., Zhang, Q., Guo, Sh., Ren, J., Li,Sh., Ye, Y. ,Wang, Z., Huang, J., Tang, Q., Sun, Y., Peng, X., Zhang, J., He, M., Zhu, Y., Xue,
J., Wang, G .,Wu, L., An, N., Wu, L., Ma, L., Zhang, W., \& Zhang, F. (2014). Producing more grain with lower environmental costs. Nature, 514, 486-489. https://doi.org/10.1038/nature13609

Deepak, V., Elena, F., Siddhrath, J., \& Xiaolei, Z. (2019). Biomass, Biopolymer-Based Materials, and Bioenergy: Construction, Biomedical and other Industrial Application. Woodhead Publishing Series in Composites Science and Engineering, UK, 558pp.

Fillery, I. R. P., Simpson, J. R., \& De Datta, S. K. (1984). Influence of field environment and fertilizer management on ammonia loss from flooded rice. Soil Science Society of America Journal 48, 914920.

https://doi.org/10.2136/sssaj1984.03615995004800 040043x

Gong, W.W., Zhang, Y.S., Huang, X.F., \& Luan, S. J. (2013). High-resolution measurement of ammonia emissions from fertilization of vegetable and rice crops in the Pearl River Delta Region, China. Atmospheric Environment, 65, 1-10. https://doi.org/10.1016/J.ATMOSENV.2012.08.02 7

Gordon, R. (2016). Where is my 3D printed polypropylene? IDTechEx. Retrieved on $16^{\text {th }}$ July 2020 from https://www.idtechex.com/fr/researcharticle/where-is-my-3d-printed-polypropylene/9801

Jamshidian, M., Tehrany, E. A., Imran, M., Jacquot, M., \& Desobry, S. (2010). Poly-Lactic Acid: Production, applications, nanocomposites, and release studies. Comprehensive Reviews in Food Science and Food Safety, 9, 552-571. https://doi.org/10.1111/j.15414337.2010.00126.x

Kochesfahani, S. H. (2016). Improving PLA-Based Material for 3-D Printers using fused deposition modeling. Plastics Engineering. Retrieved on $6^{\text {th }}$ July http://read.nxtbook.com/wiley/plasticsengineerin g/may2016/technicalpaper_improvingpla.html

Leuning, R., Freney, J. R., Denmead, O. T., \& Simpson, J. R. (1985). A sampler for measuring atmospheric ammonia flux. Atmospheric Environment, 19, 1117-1124. https://doi.org/10.1016/0004-6981(85)90196-9

Meade, G., Pierce, K., Doherty, J. V. O., Mueller, C., Lanigan, G., \& Cabe, T. M. (2011). Agriculture, 


\section{Sabrina et al. / Basrah J. Agric. Sci., 34(Special Issue 1): 11-20, 2021}

ecosystems and environment ammonia and nitrous oxide emissions following land application of high and low nitrogen pig manures to winter wheat at three growth stages. Agriculture, Ecosystems and Environment, 140, 208-217. https://doi.org/10.1016/j.agee.2010.12.007

SIMPLIFY3D® (2019). Retrieved on $16^{\text {th }}$ July 2020 https://www.simplify3d.com/support/materialsguide

Soares, J. R., Cantarella, H., \& Menegale, M. L. de C. (2012). Ammonia volatilization losses from surface-applied urea with urease and nitrification inhibitors. Soil Biology and Biochemistry, 52, 8289. https://doi.org/10.1016/j.soilbio.2012.04.019

Srivatsan T. S., \& Sudarshan, T. S. (2015). Additive Manufacturing Innovations, Advances, and Applications. Boca Raton: CRC Press, Vol. 9, 460pp. https://doi.org/10.1201/b19360

Wang, Z. H., Liu, X. J., Ju, X. T., Zhang, F. S., \& Malhi, S. S. (2004). Ammonia volatilization loss from surface-broadcast urea: Comparison of vented- and closed-chamber methods and loss in winter wheat-summer maize rotation in North China Plain. Communications in Soil Science and Plant Analysis, 35, 2917-2939. https://doi.org/10.1081/CSS-200036499

Wang, H., Zhang, D., Zhang, Y., Zhai, L., Yin, B., Zhou, F., Geng, Y., Pan, J., Luo, J., Gu, B. \& Liu, H. (2018). Ammonia emissions from paddy fields are underestimated in China. Environmental Pollution, 235, 482-488. https://doi.org/10.1016/j.envpol.2017.12.103

Wittbrodt, B., \& Pearce, J. M. (2015). The effects of PLA color on material properties of 3-D printed components. Additive Manufacturing, 8, 110-116. https://doi.org/10.1016/j.addma.2015.09.006

Wojtyła, S., Klama, P., \& Baran, T. (2017). Is 3D printing safe? Analysis of the thermal treatment of thermoplastics: ABS, PLA, PET, and nylon.
Journal of Occupational and Environmental Hygiene, 14, D80-D85. https://doi.org/10.1080/15459624.2017.1285489

Xu, J., Peng, S., Yang, S., \& Wang, W. (2012). Ammonia volatilization losses from a rice paddy with different irrigation and nitrogen managements. Agricultural Water Management, 104, 184-192. https://doi.org/10.1016/j.agwat.2011.12.013

Yan, X., Cai, Z., Yang, R., Ti, C., Xia, Y., Li, F., Wang, J., \& Ma, A. (2011). Nitrogen budget and riverine nitrogen output in a rice paddy dominated agricultural watershed in eastern China. Biogeochemistry, 106, 489-501. https://doi.org/10.1007/s10533-010-9528-0

Yang, Y., Zhou, C., Li, N., Han, K., Meng, Y., Tian, X., \& Wang, L. (2015). Effects of conservation tillage practices on ammonia emissions from Loess Plateau rain-fed winter wheat fields. Atmospheric Environment, $\quad 104$ 59-68. https://doi.org/10.1016/j.atmosenv.2015.01.007

Yang, Y., Ni, X., Liu, B., Tao, L., Yu, L., Wang, Q., Yang, Y., Liu, J. \& Wu, Y. (2019). Measuring field ammonia emissions and canopy ammonia fluxes in agriculture using portable ammonia detector method. Journal of Cleaner Production, 216 , $542-551$. https://doi.org/10.1016/j.jclepro.2018.12.109

Yu, C. T., Lai, C. C., Wang, F. M., Hsiao, H. T., Liu, L. C., Teng, W. F., Chang, H.Y., Chien, F. M., \& Chen, C. M. (2019). Preparation of acrylonitrilebutadiene-styrene copolymer (ABS)/polylactic acid (PLA) biomass alloys with $\mathrm{BaSO} 4$ and their feasible evaluation for the housing of loudspeakers. Materials Letters, 251, 52-56. https://doi.org/10.1016/j.matlet.2019.05.041

Zhang, J. W., Wang, Y. L., Xue, R. \& Ming-bao, L. (2013). Progress of advanced and practical $\mathrm{NH}_{3}$ measurement technology in atmospheric environment. Transducer \& Microsystem Technologies, 32, 10-14. 